\title{
ORIGINAL RESEARCH

EFFECTIVENESS OF RESISTANCE TRAINING ON THE
STRENGTH OF SCAPULO-HUMERAL MUSCLES AND
ABDOMINALS IN MALE VOLLEY BALL PLAYERS

V. Diwakar ${ }^{1}$

A.Viswanath Reddy ${ }^{2}$

K. Madhavi ${ }^{3}$

\section{ABSTRACT}

Background: Volleyball is a sportive modality that requires strength in the upper and lower extremities along with the trunk musculature. The improvement of muscular strength is very important along with agility and flexibility for a volleyball player. Aim of the study to find the effectiveness of resistance training on the strength of scapulo-humeral muscles and abdominals in male volley ball players. Objectives of this study is find out the effect of resistance training on the strength of the scapulohumeral muscles by measuring peak torque by using an isokinetic dynamometer and to find out the effect of resistance training on strength of abdominals through 1RM test.

Methods: A group of 30 male volleyball players who have fulfilled the inclusion criteria were assigned into two groups control and experimental groups each consisting of 15 subjects. The subjects of the experimental group underwent resistance training under my supervision and the subjects of the control group done the same protocol unsupervised for 6 weeks.

Results: There was significant improvement in the strength of scapula-humeral muscles and abdominals in the experimental group when compared to the control group when the pre and post intervention values were measured $(p=0.05)$.

Conclusion: Resistance training under supervision of the therapist resulted in significant improvement in strength of the scapulo-humeral muscles and abdominals in the male volleyball players.

Key words: Resistance training, Strength, Peak torque, Biodex, scapula-humeral muscles, abdominals.

Received $3^{\text {rd }}$ July 2014, revised $20^{\text {th }}$ July 2014, accepted $27^{\text {th }}$ July 2014

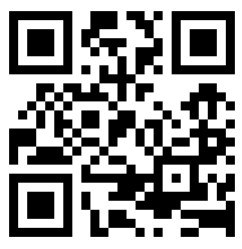

DOI: $10.15621 / \mathrm{ijphy/2014/v1i3/53466}$

www.ijphy.org

\section{CORRESPONDING AUTHOR}

\footnotetext{
${ }^{2}$ Associate Professor

${ }^{3}$ Professor and Principal

College of Physiotherapy,

Sri Venkateswara Institute of Medical

Sciences, Tirupati, Andhra Pradesh, India.
}

\author{
${ }^{1}$ V. Diwakar, \\ MPT Post graduate Student, \\ College of Physiotherapy, \\ Sri Venkateswara Institute of Medical \\ Sciences, Tirupati, Andhra Pradesh, India. \\ e-Mail: diwaphysio2007@gmail.com
}




\section{INTRODUCTION}

Volleyball is a sportive modality that requires strength in the upper and lower extremities along with the trunk musculature. The improvement of muscular strength is very important along with agility and flexibility for a volleyball player. The ball is usually played with the hands or arms, but players can legally strike or push (short contact) the ball with any part of the body. A well structured volleyball training program can increase explosive power, vertical jump height, speed and agility around the court.

Most volleyball injuries are a result of overuse and overtraining. Playing on multiple teams during the year gives the young athlete less time for proper rest between practices and games. Lack of strength and flexibility in the core, shoulders, and legs can lead to poor form in the athlete's jumps and volleys, resulting in injury.

Resistance Training(RT) can improve players' maximal force and power production, reduce the incidence of injury, and contribute to faster injury recovery times, thereby minimizing the number of missed practice sessions and competitions. 1,2 There are specific forms in which overload may be introduced during RT. ${ }^{3}$ From the various training variables, it appears that training intensity is the most important parameter to consider when designing an RT program to target maximum strengthened in high level athletes. ${ }^{4,5}$

Research has shown that RT with external loads corresponding to $80-100 \%$ of 1repetition maximum (1RM) are most effective for increasing maximal dynamic strength, because this loading range appears to maximally recruit muscle fibers and produce further neural adaptations. Among this intensity range of $80-100 \%$ of $1 \mathrm{RM}$, experienced weight-trained athletes routinely invest their RT time in the use of excessive heavy loads ( $>90 \%$ of $1 \mathrm{RM}$ ). The effective increase in maximal strength can be achieved by training at relative intensities.

The assessment of muscle strength can be done using several testing methods such as manual muscle testing, hand held dynamometry (HHD) and motor-driven dynamometry. The first one, rating muscle strength from 0 to 5 , is considered a subjective tool with poor quantitative precision. ${ }^{6}$ The other two methods are more objective tools. HHD has the advantage of being user-friendly and inexpensive with an established reliability in several populations ${ }^{7,8}$ and muscle groups $^{9,10}$. However, a major drawback of HHD entails the lack of standardization of the participants' starting position and the placement of the assessor and the dynamometer.

Consequently, motor-driven dynamometry is still considered the gold-standard with a thorough standardization and the results are not influenced by a strength imbalance between the participant and the assessor. Moreover, it allows performing both isometric and isokinetic testing. Although, isometric testing is shown to be a reliable and valid method. ${ }^{11,12} \quad$ Isokinetic testing is more representative of muscle action during dynamic tasks of daily life. Hence, isokinetic testing is used for assessing the strength of scapulo-humeral muscles in this study.

Abdominal curl up testing is used for assessing the strength of abdominals in this study. This study is done to find the effect of supervised and unsupervised resistance training on the strength of the scapula-humeral muscles and abdominals in male volleyball players.

\section{MATERIALS AND METHODOLOGY}

\section{METHODOLOGY:}

- Study design : Experimental study design (before $\&$ after with control group)

- Sampling : Simple random sampling

- Setting : Sri Venkateswara arts and science college \& Sri Venkateswara institute of medical sciences, Tirupati, A.P

- Sample size : 30 subjects, each group(15)

- Study duration : 6 weeks, 5days/week

\section{MATERIALS:}

- Isokinetic analyser to evaluate the peak torque of scapulo-humeral muscles

- Barbells to strengthen shoulder flexors and abductors and elbow extensors

- Pull- down station to strengthen shoulder extensors and adductors

- Sit- up station to strengthen shoulder flexors and abductors

\section{CRITERIA OF THE STUDY}

Inclusion criteria: Age group: 18 - 24 years, Professional male volley ball players and $\mathrm{BMI}=18$ $-25$

Exclusion criteria: Previous history of back pain with known etiology, any shoulder pathology, neck pathology, recent chest injury, fractures of upper limb and lower limb and BMI above 25

\section{OUTCOME MEASURES}

Measurement of scapula humeral muscle strength by using isokinetic dynamometer. Each subject 
performs a practice trial consisting of three sub maximal shoulder flexion, extension, abduction and adduction at $60 \% \mathrm{~s}, 90 \% \mathrm{~s}, 120^{\circ} / \mathrm{s}$ angular velocity before recording the data. The evaluation of strength training involved the measurement of peak torque of shoulder flexors, extensors, abductors and adductors by using the Isokinetic analyser (Biodex) with angular velocities of $60 \%$, $90^{\circ} / \mathrm{s}, 120^{\circ} / \mathrm{s}$.

Measuring the abdominal strength by using abdominal curl up test. Abdominal strength was measured by using a 1RM test. Subjects were positioned in supine hook lying on a flat surface, keeping the middle and lower back flat on the surface. The number of repetitions performed per minute were measured baseline and after 6 weeks. A prior informed consent was obtained from all the participants after fully explaining the research protocol.

\section{PROCEDURE}

A group of 30 male volleyball players who have fulfilled the inclusion criteria were assigned into two groups control and experimental groups each consisting of 15 subjects. The subjects of the experimental group underwent resistance training under my supervision and the subjects of the control group done the same protocol unsupervised for 6 weeks. The demographic data were collected from each subject and the purpose of the study was explained to all the subjects.

\section{INTERVENTION}

Resistance training was given to both groups, supervised training for the experimental group and unsupervised training to the control group. The intervention included warm up for 10 minutes, stretching for 12 minutes, resistance training for 30 minutes, cool down for 8 minutes for both the groups.

\section{PROTOCOL FOR EXPERIMENTAL GROUP}

Warm up period conducted for 10 minutes, which include Jogging, Arm circles, General Mobility exercises.

Stretching for 12 minutes including Neck stretches, Upper extremity stretches- biceps, triceps, deltoid and forearm long flexors. Lower extremity stretches-quadriceps, hamstrings and calf muscles, trunk stretches. Resistance training exercises for 30 minutes
Morning session: To strengthen Scapulo-humeral muscles

- Bench press(shoulder flexors, adductors and elbow extensors)

- Shoulder shrugs(shoulder girdle elevators)

- Seated press (overhead) ( shoulder flexors and abductors)

- Let pull down (shoulder extensors and adductors)

- Bent over row (shoulder extensors)

Evening session: To strengthen abdominals

- Bent knee curls up

- Reverse sit up

- Lower abdominal exercises

Cool down period of 8 minutes which includes Relaxation exercises for Upper, lower extremity muscles and relaxed breathing exercises.

The above exercises were performed 10 repetitions per set, total of 3sets are performed for each session. The session consisted of one session in the morning, which conducted scapulo-humeral muscle resistance training and one session in the evening which included abdominal muscle resistance training. These two sessions were conducted in a day. Duration of RT per each session is one hour. This RT was conducted 5days in a week for 6-weeks.

\section{PROTOCOL FOR CONTROL GROUP}

The subjects in the control group performed the same exercise protocol as experimental group but without supervision for period of 6 -week training program.

\section{STUDY ALGORITHM: Appendix - 1}

\section{STATISTICAL ANALYSIS}

Statistical analysis has been carried out to analyze the significant impact of the treatments issued to the subjects of both control and experimental groups by using IBM SPSS Inc.20.0 version. All 30 subjects completed the entire study protocol as defined by 6-weeks in the training sessions. Statistical tools such as independent sample t-test and paired sample t-test has been applied to the outcome measure - peak torque for shoulder flexion, extension, abduction, adduction at $60^{\circ} / \mathrm{s}$, $90^{\circ} / \mathrm{s}, 120^{\circ} \%$ s. and abdominal curl up test. 
Table-1:

Mean difference of pre and post intervention of abdominal curl up test of the experimental and control group

\begin{tabular}{|c|c|c|c|c|c|}
\hline Group & $\begin{array}{c}\text { Mean } \\
\text { Difference }\end{array}$ & $\begin{array}{l}\text { Standard } \\
\text { Deviation }\end{array}$ & t- value & df & p-value \\
\hline Experimental (Pre-Post) & 9.00 & 1.31 & 26.62 & 14 & 0.000 \\
\hline Control (Pre-Post) & 4.33 & 1.05 & 16.04 & 14 & 0.000 \\
\hline
\end{tabular}

Pre - post values for the abdominal curl up test score in experimental and control group, t-test for independent sample observation has been utilized. It is observed that the post values of supervised experimental group have shown significant changes to the subjects.
The following diagrammatic representation shows the pre and post mean difference values of abdominal strength in experimental and control group.

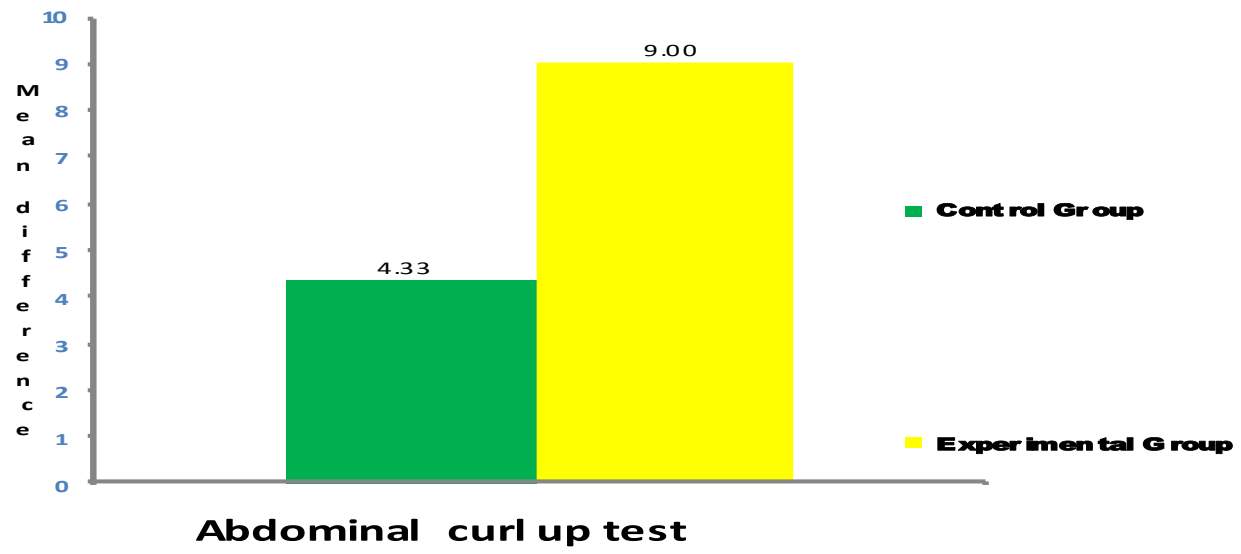

Graph: 1 Pre and Post values of Abdominal curl up test

Table-2

Mean difference of pre and post intervention of scapulo-humeral strength measure of the

\begin{tabular}{|c|c|c|c|c|c|}
\hline $\begin{array}{l}\text { Parameter } \\
\text { (Pre-Post) }\end{array}$ & $\begin{array}{c}\text { Mean } \\
\text { Difference }\end{array}$ & $\begin{array}{l}\text { Standard } \\
\text { Deviation }\end{array}$ & t- value & Df & p-value \\
\hline $\begin{array}{c}\text { Flexion } 60 \% / \mathrm{s} \\
90 \% / \mathrm{s} \\
120 \% / \mathrm{s}\end{array}$ & $\begin{array}{l}11.48 \\
10.05 \\
10.36\end{array}$ & $\begin{array}{l}2.48 \\
2.81 \\
2.88\end{array}$ & $\begin{array}{l}17.93 \\
13.83 \\
13.94\end{array}$ & $\begin{array}{l}14 \\
14 \\
14\end{array}$ & $\begin{array}{l}0.000 \\
0.000 \\
0.000\end{array}$ \\
\hline $\begin{array}{c}\text { Extension60 } / \mathrm{s} \\
90 \% / \mathrm{s} \\
120 \% / \mathrm{s}\end{array}$ & $\begin{array}{l}10.81 \\
10.25 \\
10.25\end{array}$ & $\begin{array}{l}1.96 \\
2.40 \\
2.20\end{array}$ & $\begin{array}{l}21.31 \\
16.52 \\
18.02\end{array}$ & $\begin{array}{l}14 \\
14 \\
14\end{array}$ & $\begin{array}{l}0.000 \\
0.000 \\
0.000\end{array}$ \\
\hline $\begin{array}{c}\text { Abduction60 } \% \text { s } \\
90 \% / \mathrm{s} \\
120 \% \mathrm{~s}\end{array}$ & $\begin{array}{l}10.30 \\
15.47 \\
18.24\end{array}$ & $\begin{array}{l}1.85 \\
5.34 \\
7.86\end{array}$ & $\begin{array}{c}21.60 \\
11.22 \\
9.20\end{array}$ & $\begin{array}{l}14 \\
14 \\
14\end{array}$ & $\begin{array}{l}0.000 \\
0.000 \\
0.000\end{array}$ \\
\hline $\begin{array}{c}\text { Adduction60 } \% \text { s } \\
90 \% / \mathrm{s} \\
120 \% \mathrm{~s}\end{array}$ & $\begin{array}{c}9.86 \\
10.21 \\
11.30\end{array}$ & $\begin{array}{l}2.20 \\
1.78 \\
2.90\end{array}$ & $\begin{array}{l}17.39 \\
22.20 \\
15.07\end{array}$ & $\begin{array}{l}14 \\
14 \\
14\end{array}$ & $\begin{array}{l}0.000 \\
0.000 \\
0.000\end{array}$ \\
\hline $\begin{array}{l}\text { Experimental gro } \\
\text { Pre- post values for } \\
120^{\circ} \text { s angular velc } \\
\text { score in the exp }\end{array}$ & $\begin{array}{l}\text { peak torqu } \\
\text { ity scapulo-h1 } \\
\text { imental grol }\end{array}$ & $\begin{array}{l}60^{\circ} / \mathrm{s}, 90^{\circ} / \mathrm{s}, \\
\text { ral strength } \\
\text { t- test for }\end{array}$ & \multicolumn{3}{|c|}{$\begin{array}{l}\text { independent sample observations has been } \\
\text { utilized. It is observed that the post values of } \\
\text { supervised experimental group have shown } \\
\text { significant changes to the subjects. }\end{array}$} \\
\hline
\end{tabular}


Table-3

Mean difference of pre and post intervention of scapulo-humeral strength measure of the control group

\begin{tabular}{|c|c|c|c|c|c|}
\hline Parameter (Pre-Post) & $\begin{array}{c}\text { Mean } \\
\text { Difference }\end{array}$ & $\begin{array}{l}\text { Standard } \\
\text { Deviation }\end{array}$ & t-value & df & p-value \\
\hline $\begin{array}{c}\text { Flexion } 60 \% \text { s } \\
90 \% \text { s } \\
120 \% s\end{array}$ & $\begin{array}{l}4.40 \\
4.53 \\
3.68\end{array}$ & $\begin{array}{l}1.03 \\
1.14 \\
1.51\end{array}$ & $\begin{array}{c}16.56 \\
15.37 \\
9.46\end{array}$ & $\begin{array}{l}14 \\
14 \\
14\end{array}$ & $\begin{array}{l}0.000 \\
0.000 \\
0.000\end{array}$ \\
\hline $\begin{array}{c}\text { Extension } 60 \% \text { s } \\
90 \% / \mathrm{s} \\
120^{\circ} / \mathrm{s}\end{array}$ & $\begin{array}{l}4.21 \\
4.49 \\
4.51\end{array}$ & $\begin{array}{l}1.24 \\
1.35 \\
1.47\end{array}$ & $\begin{array}{l}13.21 \\
12.86 \\
11.91\end{array}$ & $\begin{array}{l}14 \\
14 \\
14\end{array}$ & $\begin{array}{l}0.000 \\
0.000 \\
0.000\end{array}$ \\
\hline $\begin{array}{c}\text { Abduction60 } 60 \\
90 \% \text { s } \\
120 \% / \mathrm{s}\end{array}$ & $\begin{array}{l}4.21 \\
4.20 \\
3.85\end{array}$ & $\begin{array}{l}0.99 \\
1.06 \\
1.19\end{array}$ & $\begin{array}{l}16.52 \\
15.33 \\
12.54\end{array}$ & $\begin{array}{l}14 \\
14 \\
14\end{array}$ & $\begin{array}{l}0.000 \\
0.000 \\
0.000\end{array}$ \\
\hline $\begin{array}{c}\text { Adduction60 } \% \text { s } \\
90 \% \text { s } \\
120 \% / s\end{array}$ & $\begin{array}{l}3.99 \\
4.16 \\
4.15\end{array}$ & $\begin{array}{l}1.27 \\
1.75 \\
1.48\end{array}$ & $\begin{array}{c}12.16 \\
9.19 \\
10.88\end{array}$ & $\begin{array}{l}14 \\
14 \\
14\end{array}$ & $\begin{array}{l}0.000 \\
0.000 \\
0.000\end{array}$ \\
\hline
\end{tabular}

Pre- post values for the peak torque in $60^{\circ} / \mathrm{s}, 90^{\circ} / \mathrm{s}$, $120 \%$ s angular velocity scapulo-humeral strength score in the control group, t- test for independent sample observations has been utilized. It is observed that the post values of supervised experimental group have shown significant changes to the subjects.

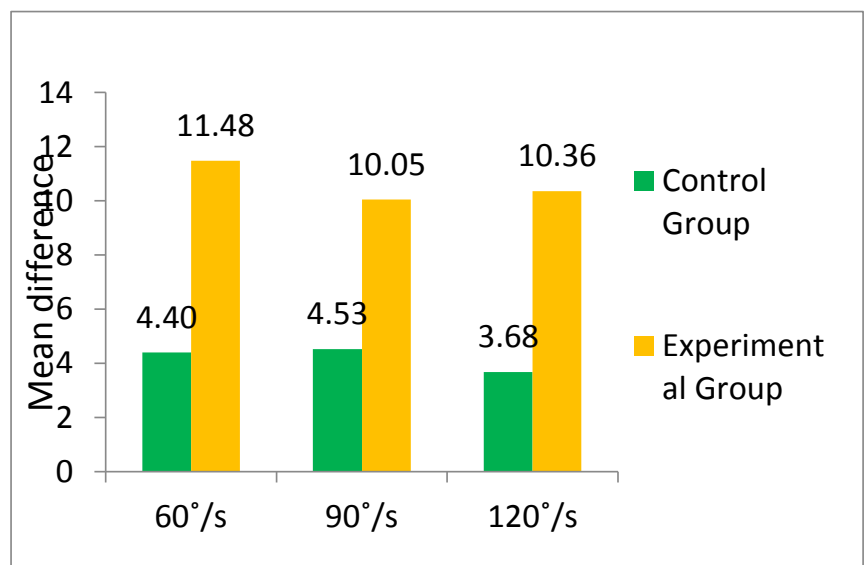

The following diagrammatic representation shows the pre and post means difference values of shoulder flexors, extensors, abductors and adductors of the control and experimental groups.

Graph 2: Pre and Post values of shoulder flexors Graph3: Pre and Post values of shoulder extensors

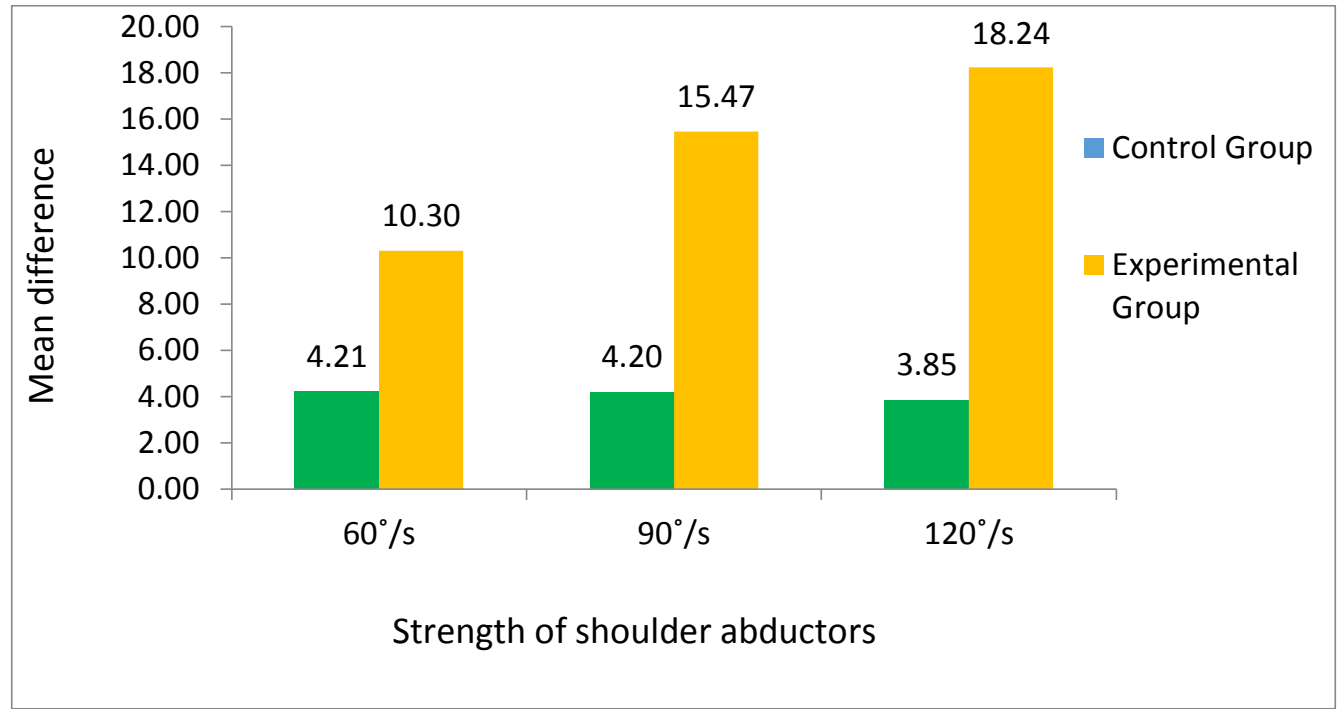

Graph 4: Pre and Post values of shoulder abductors 


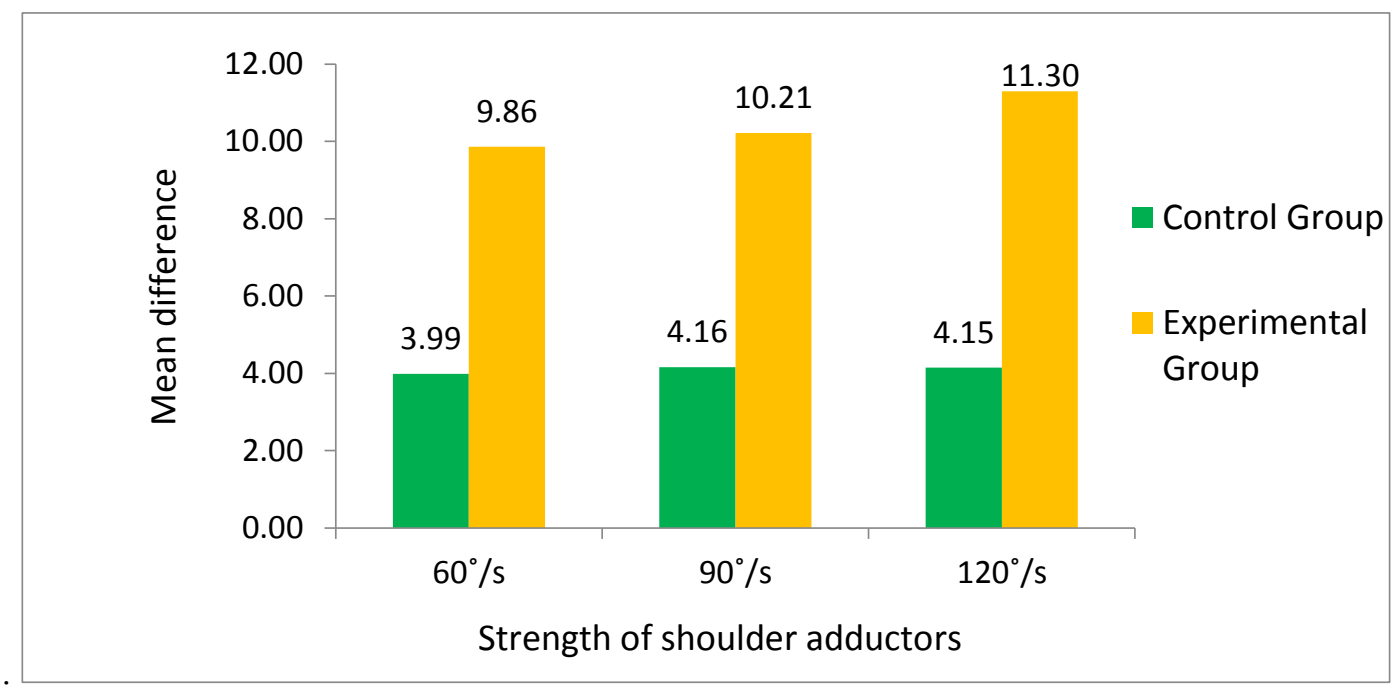

Graph 5: Pre and Post values of shoulder adductors

\section{RESULTS}

After a 6- week intervention period, the subjects in the experimental and control group had shown improvement with outcome measures; but on comparing control group with experimental groups, the experimental group had shown a statistically significant improvement at 0.001 levels with the outcome measures, i.e. Isokinetic peak torque at $60 \% \mathrm{~s}, 90 \% \mathrm{~s}, 120 \% \mathrm{~s}$ shows $(\mathrm{p}=0.00)$ and abdominal curl up test and its score shows $(\mathrm{p}=0.00)$.

\section{DISCUSSION}

In the present study out of 30 subjects, 15 subjects were randomly selected for supervised resistance training (experimental group) and 15 subjects for unsupervised resistance training (control group). They have completed the course of resistance training (6 weeks) as per the prescribed protocol. The strength of the scapulo-humeral muscles and abdominals in male volleyball players showed significant improvement after 6 weeks of resistance training for experimental $\operatorname{group}(p<$ $0.001)$ and for control group $(p<0.005)$.

The aim of the study is to evaluate the effectiveness of resistance training on the strength of the scapulo-humeral muscles and abdominals in subjects with male volleyball players. The design of RT programs for sport performance is that the speed of muscle shortening during training should be similar to those speeds used during the event. For example, many sports require a high velocity of movement. Several studies have shown that RT programs use high velocity of movements in a sport specific movement pattern to produce superior gains in strength/power- oriented sports. ${ }^{13,14,15}$

The perfect training regimen for optimum improvement of strength remains
controversial.The exercise prescription for RT must be tailored for the individual. The intensity is 6 to 10 repetition maximum and practiced in multiple sets of three or four. ${ }^{16,17,18}$ Clearly, strength gains are less when the number of repetitions is greater than 15. Rest days between strength workouts seem critical for optimal strength improvement. ${ }^{18}$ Therefore, a training schedule 4to5days is recommended.

Trieber FA, Lott J, et al(1998) done a study on 4week isotonic resistance training program using theraband elastic tubing and lightweight dumbbells and found significant increase in concentric shoulder rotator strength or velocity of serving or both in a group of elite-level tennis players.

Lachowetz T, Evon Jet al.(1998) studied on the effects of upper body strength training program on baseball throwing velocity in which 22 players participated in the study. They proposed the implication of the study on throwing velocity could be enhanced by using a progressive strength training program of 6 -weeks.

According to Rose St \& Rothstien JM (1982), muscle strength is increased due to adaptations occurring in the neuromuscular system due to stress during exercises. These adaptations take in the form of physiological changes in the muscle that increase the performance capability of that muscle. Resistance training may induce central nervous system changes, which can increase the number of motor units recruited, alter motor neuron firing rates, enhance motor unit synchronization during a particular movement pattern, and result in the removal of neural inhibition. ${ }^{19,20}$ An increase in muscular tension with exercise training provides the primary stimulus to initiate the relatively slow process of skeletal muscle growth, or hypertrophy. Mechanical stress on the components of the 
muscular system triggers signaling proteins to activate the genes that activate translation of messenger RNA and stimulate protein synthesis in excess of protein breakdown.Accelerated protein synthesis, particularly when combined with the effects of insulin and adequate amino acid availability, increases muscle size during RT.

\section{CONCLUSION:}

Resistance training under supervision of the therapist resulted in significant improvement in strength of the scapulo-humeral muscles and abdominals in the male volleyball players.

\section{LIMITATIONS:}

Sample size is small, Study duration is shorter and Resistance training selected only male volleyball players.

\section{RECOMMENDATIONS:}

Studies can be done both in men women and Studies can be done with outcome measures on strength measurements which is a cost affordable.

\section{REFERENCES}

1. Fleck, S.J., S. Case, J. Puhl, and P. Vanhandel. Physical and physiological characteristics of elite volleyball players. Can. J. Appl Sport Sci. 1985; 10(3): 122-126.

2. Zatsiorsky,V.M. Science and Practice of Strength Training. Champaign, Human Kinetics, $2^{\text {nd }}$ ed; 1995.

3. González-badillo, J.J., E.M.Gorostiaga, R.Arellano, and M. Izquierdo. Moderate resistance training volume produces more favorable strength gains than high or low volumes during a short-term training cycle. J.Strength Cond Res. 2005;19(3): 689-697.

4. Tan.B. Manipulating resistance training program variables to optimize maximum strength in men: A review. J. Strength Cond Res. 1999; 13(3):289-304.

5. Schmidtbleicher, D. Training for power events, Strength and Power in Sports. $2^{\text {nd }}$ ed; 1992.

6. Wadsworth CT, Krishnan R, Sear M, Harrold J, Nielsen DH. Intrarater reliability of manual muscle testing and handheld dynametric muscle testing. Phys Ther. 1987; 67(9):13421347.

7. Bohannon RW. Measuring knee extensor muscle strength. American journal of physical medicine \& rehabilitation.2001; 80(1):13-18.
8. Mahony K, Hunt A, Daley D, Sims S, Adams R .Inter-tester reliability and precision of manual muscle testing and handheld dynamometry in lower limb muscles of children with spina bifida. Phys Occup Ther Pediatr. 2009; 29(1):44-59.

9. Thorborg K, Bandholm T, Hölmich P. Hip- and knee-strength assessments using a handheld dynamometer with external belt-fixation are inter-testedreliability. Knee Surg Sports Traumatol Arthrosc. 2013; 21(3):550-555.

10. Hogrel J-Y, Payan CA, Ollivier G, Tanant V, Attarian $S$ et al. Development of a french isometric strength normative database for adults using quantitative muscle esting. Arch Phys Med Rehabil. 2007; 88(10):1289-1297.

11. Thorborg K, Petersen J, Magnusson SP, HölmichP. Clinical assessment of hip strength using a handheld dynamometer is reliable. Scand J med Sci Sports. 2010; 20(3):493-501.

12. Widler KS, Glatthorn JF, Bizzini M, Impellizzeri FM, Munzinger $U$ et al. Assessment of hip abductor muscle strength. A validity and reliability study. Journal of Bone and Joint Surgery. 2009; 91(11):2666-2672.

13. Moritani, T., and H. Devries. Neural factors Versus hypertrophy in the time course of muscle strength gain. American Journal of Physical Medicine. 1979; 58(3):115-19.

14. Rube, N., and N.Secher. Effect of training on central factors on fatigue following two and one - leg static exercise in man. Acta Physiologica Scandanavica. 1990; 141(1):87-95.

15. Berger, R.A .Optimum repetition for the development of strength. Research Quarterly. 1962;33(2):334-38.

16. Lea EFebiger. Applied Exercise Physiology. $15^{\text {th }}$ ed; 1982.

17. Stone, M., and H. O'Bryant. Weight training: A Scientific Approach. $2^{\text {nd }}$ ed; 1986.

18. Deschenes.M. Short review: Motor coding and motor unit recruitment pattern. Journal of applied Sport Science Research.1989; 3(2):3339.

19. Ewing, J. et al. Effects of velocity of isokinetic training on strength, power and quadriceps muscle fiber characteristics. European Journal of Applied Physiology. 1990; 61(1-2):159-62.

20. Sale, D. Neural adaptation to resistance training. Medicine and science in sports and Exercise. 1988;20(5):135-145. 


\section{Appendix - 1}

\section{STUDY ALGORITHM}

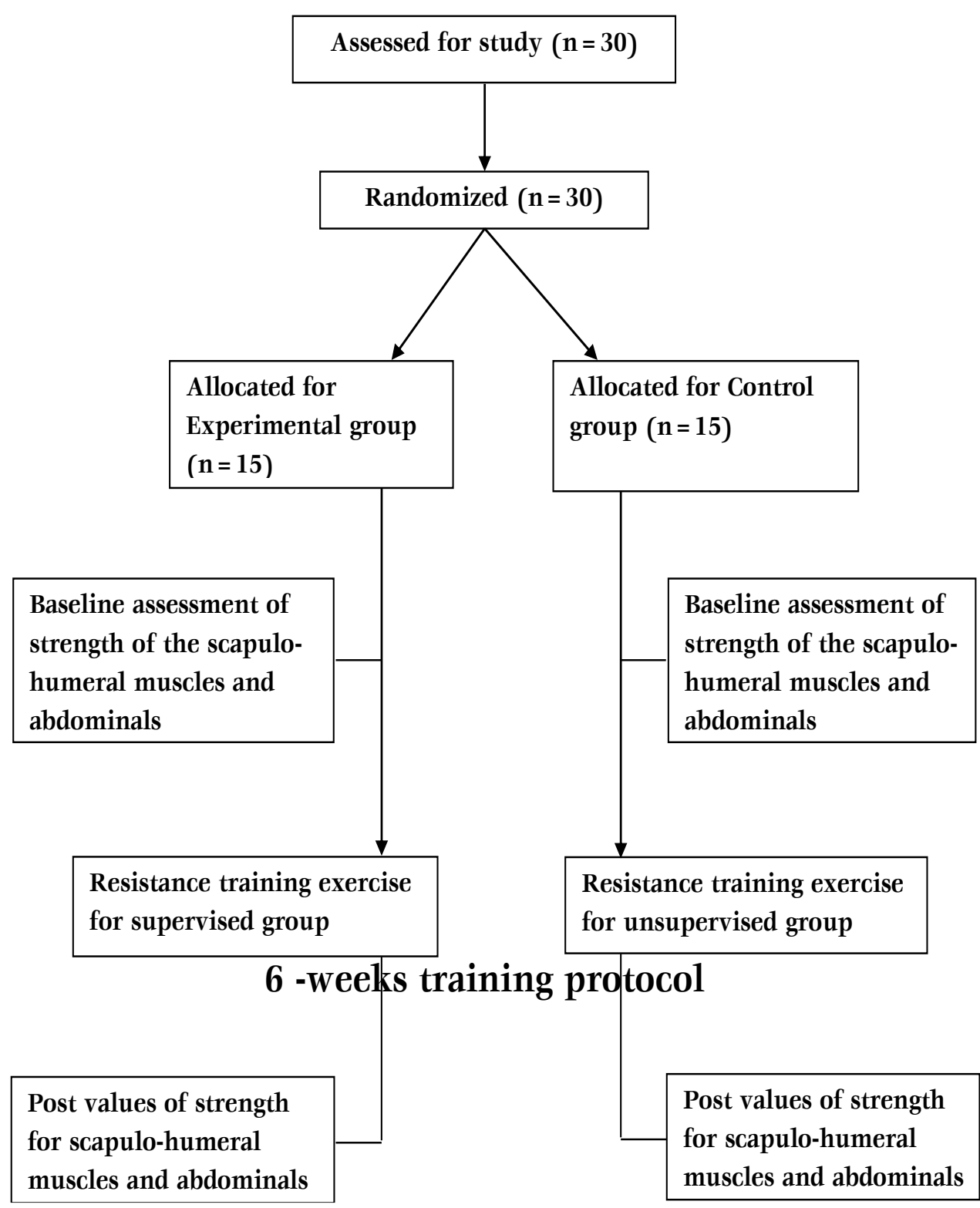

\section{How to cite this article:}

V. Diwakar, A. Viswanath Reddy, K. Madhavi. EFFECTIVENESS OF RESISTANCE TRAINNG ON THE STRENGTH OF SCAPULO-HUMERAL MUSCLES AND ABDOMINALS IN MALE VOLLEY BALL PLAYERS. Int J Physiother.2014; 1(3):127-134. 